ICES Journal of Marine Science

December 2017, Volume 74, Issue 9, Pages 2415-2426

http://dx.doi.org/10.1093/icesjms/fsx092

http://archimer.ifremer.fr/doc/00387/49805/

(C) International Council for the Exploration of the Sea 2017. All rights

reserved. For Permissions, please email:

journals.permissions@oup.com

\title{
Inferring the annual, seasonal, and spatial distributions of marine species from complementary research and commercial vessels' catch rates
}

\author{
Bourdaud Pierre ${ }^{1,{ }^{*}}$, Travers-Trolet Morgane ${ }^{1}$, Vermard Youen ${ }^{1}$, Cormon Xochitl ${ }^{1}$, Marchal Paul ${ }^{1}$ \\ *Corresponding author : Pierre Bourdaud, email address : pierre.bourdaud@ifremer.fr
}

\begin{abstract}
:
The objective of this study is to analyse at fine scale the annual, seasonal and spatial distributions of several species in the Eastern English Channel (EEC). On the one hand, data obtained from scientific surveys are not available all year through, but are considered to provide consistent yearly and spatially resolved abundance indices. On the other hand, on-board commercial data do cover the whole year, but generally provide a biased perception of stock abundance. The combination of scientific and commercial catches per unit of effort (CPUEs), standardized using a delta-generalized linear model, allowed to infer spatial and monthly dynamics of fish distributions in the EEC, which could be compared with previous knowledge on their life cycles. Considering the scientific survey as a repository, the degree of reliability of commercial CPUEs was assessed with survey-based distribution using the Local Index of Collocation. Large scale information was in agreement with literature, especially for cuttlefish. Fine scale consistency between survey and commercial data was significant for half of the 19 tested species (e.g. whiting, cod). For the other species (e.g. plaice, thornback ray), the results were inconclusive, mainly owing to poor commercial data coverage and/or to particular aspects of the species biology.
\end{abstract}

Keywords : commercial data, Eastern English Channel, seasonality, spatial distribution, survey data. 


\section{Introduction}

Ecosystem-Based Fisheries Management (EBFM) requires enhancing knowledge of ecosystem functioning, therefore allowing forecasting the impact of fisheries on salient ecosystem components (Long et al., 2015) and to design future management plans and tools including Marine Protected Areas (Meyer et al., 2007) or fishing closures (Hunter et al., 2006). This necessitates a stepwise approach, the first tier of which, and one of the most important, is to gain fine scale knowledge on the seasonal and geographic distribution of marine organisms, in general, and fish stocks in particular (Booth, 2000).

Scientific surveys have been implemented for decades to derive spatially- and yearly-resolved abundance indices of commercial fish and shellfish species (e.g. van Keeken et al., 2007). Surveys provide abundance indices, derived from standardized and controlled protocols, which allow for a wide spatial coverage associated with a weak selectivity (Verdoit et al., 2003). Survey data, however, are costly to obtain and therefore rarely provide for adequate seasonal coverage of the resource distribution. In contrast, information derived from commercial fisheries are generally available all year through. Consequently, the catch per unit of effort (CPUE), the most common and easily collected fishery-dependent index of abundance (Maunder and Punt, 2004), has the potential to reflect fish distributions. However, commercial CPUEs can generally not be used directly as abundance indicators. This is because fishers target rather than sample fish densities, and continuously adapt their activities to prevailing conditions, through technological development and tactical adaptations (Marchal et al., 2006), including discarding practices on which information is often limited (Rijnsdorp et al., 2007).

A major challenge for fisheries scientists is then to reconcile fisheries-independent and dependent information into abundance indices that consistently mirror the annual, seasonal and spatial dynamics of commercial marine species. Kristensen et al. (2014) have 
reconstructed spatial and seasonal cohorts of cod (Gadus morhua) in Skagerrak by kriging, in both time and space, data provided by survey and also by fisheries subject to a survey-like sampling protocol. To our best knowledge, however, no method has yet been developed to estimate spatio-temporal distributions of fish at high resolution, by combining survey and true commercial fisheries data.

The main objective of this paper is to provide detailed annual, seasonal and spatial distributions of major Eastern English Channel (EEC) commercial fisheries resources, using a novel approach combining fisheries-independent and -dependent information. The gain in knowledge on fine scale temporal and spatial fish distribution in the EEC will expand the scope of earlier results (e.g. Vaz et al., 2007), and strengthen the science support to an EBFM in this area. To that purpose, we (i) inferred the seasonal and spatial abundance distribution based on survey and commercial abundance data for several species in the EEC, (ii) investigated the degree of similarity of fine scale spatial distributions derived from these two data sources and (iii) investigated abundance indices derived from these data sources.

\section{Material and methods}

\subsection{Study area}

The Eastern English Channel (ICES subdivision VIId) is delimited by latitudes $49.3^{\circ} \mathrm{N}$ and $51^{\circ} \mathrm{N}$ and longitudes $2^{\circ} \mathrm{W}$ and $2^{\circ} \mathrm{E}$ (Figure 1). This shallow area constitutes a corridor between the northeast Atlantic Ocean and the North Sea, and a strategic region in the northeast Atlantic, as it hosts a very intense maritime traffic and human activities such as mixed fisheries, aggregate extraction and wind farms (Dauvin, 2012). This area is also important for several commercially important migratory species, e.g. red mullet (Mullus surmuletus) (Mahé et al., 2005), cuttlefish (Sepia officinalis) (Royer et al., 2006), mackerel 
(Scomber scombrus) (Eltink et al., 1986), herring (Clupea harengus) (ICES, 2015), or

European seabass (Dicentrarchus labrax) (Pawson et al., 2007).

Fishing is a key socio-economic activity in the region (Carpentier et al., 2009), which has also generated a strong pressure on its marine ecosystem (Molfese, 2014).

\subsection{Data}

This study is supported by two main data sources: a scientific survey (the Channel Ground Fish Survey - CGFS; Coppin and Travers-Trolet, 1989) and observations on-board commercial vessels (hereby referred to as the OBSMER French programme; Cornou et al., 2015).

The CGFS has sampled the entire EEC demersal community annually since 1988 . The survey occurs every year in October, with a systematic fixed sampling design of 88 trawling stations located between $49.3^{\circ} \mathrm{N}$ and $51.3^{\circ} \mathrm{N}$. The sampling gear is a GOV trawl with $3 \mathrm{~m}$ vertical opening, $10 \mathrm{~m}$ horizontal opening and a $20 \mathrm{~mm}$ codend. For each haul, all fish caught are sorted, identified and measured to the nearest inferior centimetre. In case of large catch, random subsampling is performed while ensuring representativeness of species and length distributions. For the current study only survey data from 1998 to 2014 were retained as this period corresponds to a relatively stable state of the community structure with no detected regime shift in species spatial distributions (Auber et al., 2015).

The CGFS provides information for a large panel of economically valuable demersal fishes and cephalopods, i.e. European seabass, red mullet, cod, whiting (Merlangius merlangus), plaice (Pleuronectes platessa), cuttlefish, squids (Loligo spp.) and thornback ray (Raja clavata). Other commercially important species such as common sole (Solea solea), herring or sardine (Sardina pilchardus), are poorly sampled by the GOV trawl (Carpentier et al., 2009), and thus have not been considered in this study. 
On-board observer programmes allow estimating catch and effort for a sample of fishing operations. Unlike other fisheries data collection programmes, e.g. building on port sampling and/or mandatory logbooks, observer's data are precisely geo-referenced and allow inferring the total catch, including the discarded fraction, and more accurate measurements of effective fishing effort. Although on-board fisheries data can generally not be collected for all the vessels belonging to a given fleet, and although the presence of observers may be perceived as overly intrusive to fishers, they offer an opportunity to derive CPUE-based abundance indicators, at a fine spatial and temporal scale.

The OBSMER programme covers the period 2003-2015. It was developed to better estimate the discards' quantity and assess catch composition. Precise information on ship characteristics (e.g. homeport, length, engine power), fishing activity (time, latitude, longitude, gear, fishing effort, targeted species assemblage) and catch composition (landings and discards of fish and commercial invertebrates) are collected for each fishing operation by scientific observers. For each fishing operation, a subsample of the catch (including both the part to be landed and the part to be discarded) is sorted, identified and measured. This data compilation has already been operated to characterize pressures exerted on communities, discarded fractions of catches, or discarding drivers (Fauconnet et al., 2015).

Spatio-temporal species distributions estimated using OBSMER data are primarily expected to corroborate previous knowledge on these species' life cycles. In addition, they could reflect species distributions as observed using scientific surveys (considered as a reference) in converging time lapse. However, because species' spatial distributions are dynamic and vary from one time step to another, and because fishers continuously adapt to prevailing conditions (Eigaard et al., 2014), time and spatial variations in CPUE reflect two entangled signals prompted by fisher's plasticity and stock fluctuations. Using CPUEs to reflect time changes in 
stock abundance therefore requires to preliminarily filter out the skipper effect signal it originally contains (Maunder and Punt, 2004).

\subsection{Standardizing survey and commercial catch rates}

Surveys and commercial fisheries operate at different temporal and spatial scales, with different gears and strategies, thereby targeting dissimilar species assemblages and/or size ranges. The first step of this study was to identify common temporal and spatial scales, then to select a common pool of representative species and size ranges, and finally to standardize survey and commercial catchabilities using a delta- Generalized Linear Model (GLM) approach.

The temporal scale retained is the month, while the spatial scale considered is cells of $0.3^{\circ} \mathrm{x}$ $0.3^{\circ}\left(\sim 700 \mathrm{~km}^{2}\right)$. These seasonal and spatial scales result from a trade-off between having a sufficient amount of data and maintaining a sufficient level of precision, as described further. Based on these small-scale spatio-temporal units, a mean CPUE index in number of individuals caught per hour is calculated separately from OBSMER data for each month and from CGFS data (only for October) for a set of demersal species (Table 1). These species have been selected based on their economic importance, relative abundance and/or catchability by the survey gear being considered. Survey data were only kept from 2005 to 2014 for the cephalopods (i.e. Sepia officinalis and Loligo spp.), as no length information is available for these species before 2005. To harmonize the survey and commercial gears' selectivities of the species being considered, we used a common length threshold $\left(\mathrm{L}_{\mathrm{s}}\right)$ above which a species is considered to be correctly selected by the different gears (Table 1). $L_{s}$ was graphically determined from length distribution for each species following the method used by Ravard et al. (2014): in commercial data most of the length-frequency were unimodal and $L_{s}$ was approximately set for each species at the length of the highest mode of the different gears combined. In our study, $\mathrm{L}_{\mathrm{s}}$ mainly corresponded to the official minimum landing sizes 
for the few species concerned. The potential case of a different selectivity of large individuals to particular gears (e.g. Bertignac et al., 2012) is not considered in this study.

OBSMER data were filtered to avoid abundance overestimation. Thus, for each species and each size, only hauls with all the subsamples representing at least $5 \%$ of the total catch weights each were kept for further calculations. Furthermore, to obtain a clear overview of abundance for each demersal species being studied, only fishing gears sufficiently represented (i.e. > 10 observations for a given species) were kept in the analysis.

Finally, we adjusted the remaining catchability differences by standardizing CPUE values derived from both OBSMER and survey data. This was operated by applying a delta-GLM to the CPUEs of each species under consideration. The delta-GLM first fits the probability of observing a zero catch as a function of the explanatory variables, and then fits another GLM to the non-zero catches (Maunder and Punt, 2004; Meissa et al., 2008; among others). The probability of presence is based on the binomial distribution after a binary recoding $(0=$ absence and $1=$ presence). For hauls with positive CPUE a logarithmic transformation was first applied on data in order to homogenize variances and to transform the multiplicative effects into additive effects (Meissa et al., 2008).

The delta-GLM for OBSMER data contains a maximum of six explanatory variables:

$\operatorname{logit}\left(p_{i, a, m, y}^{>0}\right)=\beta_{a} \delta_{m}+\lambda_{y}+\rho_{g} \tau+v_{s}$

$\log \left(\mathrm{IA}_{\mathrm{i}, \mathrm{a}, \mathrm{m}, \mathrm{y}}\right)=\beta_{\mathrm{a}} \delta_{\mathrm{m}}+\lambda_{\mathrm{y}}+\rho_{\mathrm{g}} \tau+\mathrm{v}_{\mathrm{s}}+\varepsilon_{\mathrm{i}, \mathrm{a}, \mathrm{m}, \mathrm{y}}$ where $p_{i, a, m, y}^{>0}$ is the mean presence probability and $\mathrm{IA}_{\mathrm{i}, \mathrm{a}, \mathrm{m}, \mathrm{y}}$ the CPUE of a species caught by vessel $i$ of length $\tau$ rigged with gear $g$ (e.g. bottom otter trawl, trammel net), fishing in $\left(0.3^{\circ} \mathrm{x}\right.$ $0.3^{\circ}$ ) area $a$, year $y$ and month $m . \beta a$ is the area effect of the fishing operation (treated as factor), $\delta_{m}$ is the month effect of the fishing operation, $\rho_{g}$ is the gear effect, $\lambda_{y}$ is the annual effect, $v_{s}$ isthe sediment effect, which accounts for small scale habitat variability and is 
decomposed into five categories $s$ : mud, fine sand, coarse sand, gravel and pebble, based on a sediment map of EEC from Larsonneur et al. (1982), and $\varepsilon_{\mathrm{i}, \mathrm{a}, \mathrm{m}, \mathrm{y}}$ a term of residual error.

179 Sediments are kept because they proved to have the strongest influence on the distribution of species in the shallow Eastern English Channel, compared with, e.g. depth, temperature and salinity (see Carpentier et al., 2009). Engine power information was also available but only vessel length was kept as these two variables are usually highly correlated for bottom otter trawlers ( $\mathrm{r}=0.94$ using OBSMER data), the main size-varied vessels of the available commercial data.

CGFS survey data are always collected in October (i.e. no month effect) with the same research vessel (i.e. no vessel or gear effects), hence the previous formula was reduced to the following, with a maximum of three explanatory variables:

$\operatorname{logit}\left(\mathrm{p}_{\mathrm{a}, \mathrm{y}}^{>0}\right)=\beta_{\mathrm{a}}+\lambda_{\mathrm{y}}+\mathrm{v}_{\mathrm{s}}$

$\log \left(\mathrm{IA}_{\mathrm{i}, \mathrm{a}, \mathrm{m}, \mathrm{y}}\right)=\beta_{\mathrm{a}}+\lambda_{\mathrm{y}}+\mathrm{v}_{\mathrm{s}}+\varepsilon_{\mathrm{a}, \mathrm{y}}$

Models' retained explanatory variables were selected for each species based on Akaike information criterion (AIC). Model selection was largely influenced by the previous choice of the spatial resolution for area variable. In none of the models (1-4) an interaction term between area (or area-by-month) and year effects was considered. This requires some clarifications, given such an interaction term could potentially reveal spatial shifts in fish distribution over time.

In the analysis of commercial CPUE indices, spatio-temporal interactions were partly covered by introducing an area-by-month term. It was, however, not possible to explore the effect of introducing the higher-ranked interaction area-by-month-by-year, partly owing to the limited amount of observations available but also to opportunistic fisher's behaviour, which in combination resulted in a variable inter-annual coverage of the OBSMER dataset. In the analysis of survey abundance indices, only area-by-year effects could potentially be 
considered, since the CGFS is operated in October only. Auber et al. (2015) concluded that although October EEC fish communities were subject to a substantial spatial shift in 1997, no significant change was observed during 1998-2014, i.e. the period being considered in this analysis. Still, we did investigate a model including a spatio-annual effect. According to the AIC none of the presence/absence models and only 3 out of the 19 abundance models showed improved goodness of fit performances when an area-by-year interaction term was added (poor cod, starry smooth-hound and thornback ray), without statistically significant differences in the distribution outputs (Table S1 and S2). Furthermore, 14 out of the 19 presence/absence models did not converge with an area-by-year interaction term.

Final predictions are obtained by the product of presence probabilities and CPUE. Knowing the sediment characteristics of each area, the total abundance in each cell is computed by reallocating the environmental effects in proportions to sediment types coverage.

Finally a limit of 10 observations per cell in both OBSMER and CGFS was determined as the threshold above which the square was kept in the analysis, resulting from a trade-off between a sufficient coverage of the EEC and a consistent number of observations (Figure 2). By applying this limit and our spatial resolution to survey data, $88 \%$ of the EEC is covered (for OBSMER data this percentage is variable among month and species). In comparison, using cells of $0.4^{\circ} \times 0.4^{\circ}$ instead of $0.3^{\circ} \times 0.3^{\circ}$ leads to the representation of $90 \%$ of the Eastern English Channel, while using smaller cells of $0.2^{\circ} \times 0.2^{\circ}$ only allows representing $68 \%$ of the Eastern English Channel. Thus our choice seems to be the best trade-off between precision and coverage.

Importantly, the explained variables presented above are likely to include inherent spatial dependence (spatial autocorrelation SAC; Legendre, 1993), owing to the nature of the data at hand. As a result, the values of the dependent variables are unlikely to be conditionally independent as assumed in these models. The SAC inherent to both CGFS and OBSMER data 
was here accounted for by applying the Moran's Eigenvectors (MEV) mapping method following the protocol described by Cormon et al. (2014) with R packages \{spdep\} (Bivand et al., 2013), \{spacemakeR\} (Dray, 2013) and \{packfor\} (Dray et al., 2013). The concept of this method is to allow the translation of the spatial arrangement of the data into a set of explanatory variables through the eigenvector decomposition of data coordinate connectivity matrix previously built (Dormann et al., 2007). For OBSMER data, MEV are computed and selected for each month separately, and then integrated in the whole model set of parameters. Temporal dependencies were not examined in the study.

\subsection{Assessing the similarity between fisheries- and survey-based spatial abundance}

The data treatment described above allows to produce monthly maps of species abundance distribution. While the global seasonal patterns obtained can be compared with disparate knowledge available for some species, the degree of reliability of the fine scale spatial distribution derived from commercial data can be addressed through comparison to surveybased maps.

To quantitatively determine how similar spatial distribution derived from commercial and survey data are at fine scale, we estimated, for October, the local overlap between distributions, using the geostatistical index Local Index of Collocation (LIC, Woillez et al., 2009):

$\mathrm{LIC}=\frac{\sum z_{\text {obsmer }}(i) z_{\text {survey }}(i)}{\sqrt{\sum z_{\text {obsmer }}^{2}(i) \times \sum z_{\text {survey }}^{2}(i)}}$

where $z_{\text {obsmer }}(i)$ and $z_{\text {survey }}(i)$ are the computed abundances in area $i$, as provided by OBSMER and CGFS data, respectively. LIC was computed using R package \{RGeostats $\}$ (Renard et al., 2014). This spatial indicator is considered appropriate to assess local overlapping between two densities of population, without taking the mean abundance into account (Woillez et al., 2009). 
This index theoretically ranges between 0 , showing absolutely no match between the two spatial distributions $\left(z_{\text {obsmer }}(i)=0\right.$ if $z_{\text {survey }}(i)>0, z_{\text {survey }}(i)=0$ if $\left.z_{\text {obsmer }}(i)>0, \forall i\right)$, and 1 , demonstrating a perfect match between them $\left(z_{\text {obsmer }}(i)=z_{\text {survey }}(i), \forall i\right)$.

The significance of index values was assessed using random permutations of OBSMER abundance values against constant CGFS ones. This procedure is repeated 5000 times, and the spatial distributions derived from commercial data were considered to overlap spatial distributions derived from the CGFS survey when the actual LIC value was above the $95^{\text {th }}$ percentile of the LIC randomly permutated values.

The Horn's index (Horn, 1966) was also tested for the study, but it provides approximately the same results and is less efficient with extreme values of abundance, thus only results based on LIC are presented.

Finally, to assess the sensitivity of our results to the set of areas being considered, a jackknife resampling was operated for all species, by removing sequentially each area, and by evaluating its impact on LIC significance.

\subsection{Comparing yearly abundance indices}

Additionally to the spatial abundance, the model provides a year effect that can be used to derive an inter-annual abundance index in both survey and OBSMER data following the method of Lo et al. (1992). The time series ranges from 1998 to 2014 for survey data (20052014 for cephalopods series) and from 2003 to 2015 for OBSMER data. It is obtained by varying only the year parameter on the computation of CPUEs, and taking the mean of all areas in natural space to avoid variance disparities. Pearson's correlation index was computed to quantify the correlation between abundance indices from the two data sources.

\section{Results}

\subsection{Monthly spatial distribution patterns}


In the delta-GLM applied to commercial CPUEs, every parameters were kept, with an exception for the sediment parameter in the presence/absence model of cuttlefish (Table S3). However, area-by-month was replaced by month alone in the presence/absence models of starry smooth-hound, flounder and John Dory. In the delta-GLM applied to survey CPUEs, the parameters selection is more variable (Table S4). For example, the year parameter is not kept in both presence/absence and abundance models for tub gurnard, and the sediment one is not kept for three species: cod, pouting and tub gurnard. The area parameter was always significant and kept. The monthly spatial distribution of cuttlefish derived from the deltaGLM models applied to commercial and survey CPUEs is presented in Figure 3. This species has been chosen for illustration because it is one of the main species in terms of yields in the EEC (Royer et al., 2006). These maps are partial and do not cover the same areas over all months, owing to varying fisheries distributions. The map presented for October results from survey-based information, hence explaining its wider spatial coverage. Some informative spatial patterns can be evidenced for cuttlefish: their quasi-absence in the EEC from January to March, a coastal aggregation along the French coast in May-June, and a more offshore distribution in October-November indicate the existence of a seasonal migration pattern for this species.

\subsection{Comparison of fine scale spatial distributions from survey data and commercial}

\section{data}

The fine scale match between the spatial abundances estimated from fisheries and survey has been quantified for each species by computing the LIC value, and testing its significance with 5000 random permutations of CPUE abundances. Of the 19 tested species, 9 had a LIC significance above 95\%, 6 between $75 \%$ and 95\%, and only 4 under 75\% (Figure 4). Considering 95\% significance threshold, survey- and fisheries-based spatial distributions were therefore found to overlap for half of the species under investigation. Although the 
distribution of LIC values resulting from the permutation tests is variable among species, the results highlight that almost all species with a LIC above 0.6 showed high significance (except John Dory for which the LIC value of 0.67 falls just below the third quartile of permutations), while species with a LIC value smaller than 0.6 showed no significant overlap (except cod with a LIC of 0.52). It can also be noted that John Dory, the only species showing no significant overlap despite a LIC above 0.6 , shows a very low variability of LIC in the permutation test.

Thornback ray, poor cod, plaice and pouting had the lowest LIC values, under 0.4.

Cephalopods species, cuttlefish and squids, had intermediate LIC values of 0.50 and 0.54 , respectively, and both were between the median and the $95^{\text {th }}$ percentile. Finally, of the four flatfish species, i.e. common dab, lemon sole, European flounder and plaice, only common dab and lemon sole had a significant LIC.

\subsection{Sensitivity to areas}

In order to assess the sensitivity of the results obtained, a jackknife resampling was performed and results were analysed in regard to some characteristics of sensitive areas (Table 2). Of the 10 species for which no overlap could be evidenced, red mullet was the only one for which LIC became significant by removing one area. Red mullet original LIC significance value compared with permutations was close to 0.05 , and dropped below that threshold with the removal of either the first or second top abundance areas as derived from CGFS information (ranked $8^{\text {th }}$ and $4^{\text {th }}$ building on OBSMER data).

Among the nine species for which the LIC was significant for all areas being considered, the LIC of seven species became not significant when removing one area (Table 3). The LIC of tub gurnard, common dab, lemon sole, starry smooth-hound and lesser-spotted dogfish were thus sensitive to the absence of one particular area, ranked first or second in abundance. The LIC of cod and black seabream became not significant with the removal of one area among a 
list of 6 and 8, respectively. Their original p-values, close to the 0.05 threshold (i.e. 0.046 and 0.043), can partially explain the high number of sensitive areas.

\subsection{Rebuilding of yearly abundance index}

The year effect derived from each delta-GLM analysis can be considered as a yearly abundance index for each species. Figure 5 displays two examples of different levels of fit between survey and commercial data, ranging from good visual fit, for cod, to poor fit for black seabream. Cod abundance index shows consistent fluctuations in both survey and commercial data, with higher abundance from 2007 to 2009 followed by 4 years of lower abundance. Black seabream abundance index derived from survey displayed a general decrease from 2004 until 2014. in contrast, the index derived from commercial CPUEs shows an increase over this period. The Pearson's correlation index was computed to quantify the link between the two abundance indices produced for each species (Table 4). The results indicated that spatial overlap represented by LIC's significance is not necessarily related to concordant abundance indices time series, as most of the species with a significant LIC value have an intermediate correlation (Figure S1). Black seabream, with a significant LIC, has even the third lowest value for Pearson's correlation metrics.

\section{Discussion}

\section{Seasonal distribution patterns of the main fishing resources in the EEC}

Our results show the usefulness of fisheries data to infer, in combination with surveys, the spatial and seasonal distributions of several species. The spatial and seasonal distribution of cuttlefish, one of the main commercial species for French fleets (Royer et al., 2006), is in agreement with literature. Indeed, from the examination of landings data, cuttlefish adults are known to start migrating in October to spend winter in the Central and Western English Channel, and to be inshore in the Eastern English Channel during summer for feeding and 
reproduction (Royer et al., 2006). Other remarkable life distribution can be derived from the maps (see Figures S2-S19), like the high winter abundance of squids in the EEC, confirming previous knowledge (Royer et al., 2002), or the quasi-absence of red mullet in the East of the EEC in the beginning of the year while it concentrates in the East central part of the EEC in the end of the year, which adheres to the conclusions of Mahé et al. (2005) based on fishers' interviews. On the contrary the spatial distribution of other species remains more stable through the year, e.g. red gurnard in the centre of the EEC, or European flounder inshore except during the winter period, as described by Skerritt (2010). Finally punctual abundance or absence can be detected, like the high concentration of cod along the English coast in June and in the Dover Strait in November, or the high presence of black seabream in the centre of the EEC in February, contrasting with its absence in the eastern part, consistent with Pawson (1995).

\section{Coherence between fisheries-dependent and -independent abundance indices}

In addition to the accordance between the global seasonal pattern produced here and the available literature, our results also show that half of the species' spatial distributions exhibited good coherence at fine scale across the two data sources. This conclusion built on an analysis of the LIC overlap metric, the statistical significance of which was quantified using a permutation test. Prior to this study, LIC values were compared with and have been found very close to Horn index values. The Horn index is another overlap metric that is commonly used in trophic ecology, and for which a value $>0.6$ is usually considered significant, without further testing (Scrimgeour and Winterbourn, 1987). Our results crosschecked this approach. Except for John Dory (i.e. LIC $=0.67$ ) and cod (i.e. LIC $=0.52$ ), every species' distribution with a LIC above 0.6 were significant. The unexpected outcome obtained for John Dory reveals a shortcoming of the method we applied to assess overlap significance. Indeed, when abundance is homogeneously spread in the entire study area (here the EEC), 
LIC can be above 0.6 and still non-significant when compared with values resulting from the permutation test. Actually, the LIC (as well as the Horn index) random permutation test can only be efficient with areas of contrasted abundance, as demonstrated by lemon sole or common dab with one area of high abundance contrasting with relatively low values.

Therefore, for the evenly distributed John Dory spatial distributions derived from survey and fisheries data can be considered to be close.

Concerning the remaining half of species with lower coherence, a number of reasons can be invoked to explain the discrepancies observed. The results of jackknife analysis demonstrated the impact of some influential areas on the result of the LIC, which cannot be observed depending on the fishers' spatial distribution in October, and highlight the sensitivity of using fine scale comparison when high abundance areas are not available. Another issue is a possible non-proportionality between CPUE and abundance (Hilborn and Walters, 1992). Indeed, commercial fisheries are expected to concentrate their activities into attractive areas ( Gillis, 2003). This issue was addressed by standardizing CPUEs using a delta-GLM, and by filtering out spatial auto-correlation. Owing to the limited amount of data, however, SAC correlations could not be computed separately for each year. This could be a concern, as species presence in a precise area/season may vary from one year to another. Thus, a more realistic approach could consist of computing SAC separately for each year, which could not be achieved in this study owing to the low number of observations in the dataset. For similar reasons, the CPUE delta-GLM could not be applied to each gear separately. Instead, observations from the different gears were analysed through the same model, where gear type was treated as an explanatory variable. This approach allowed to estimate the overall impact of gears on CPUE. However, more specific effects of gear types on CPUEs (e.g. selectivity, saturation) could not be fully addressed. In particular, the selectivity of large individuals could be a challenge, as the trawl selectivity ogive is sigmoid-shaped, while that of gillnets 
could be bell-shaped, or bi-normal, reducing the catch of larger individuals (Dickson et al., 1995). Among other potential limits, the soaking time of gillnets is much longer compared with trawls, and it is more subject to saturation effect, which could result in an asymptotic relationship between catches and fishing time (Hickford and Schiel, 1996).

Still, the lack of overlap between the spatial distributions derived from fisheries-dependent and -independent abundance indices for some species could also be explained by their actual biological and ecological characteristics. These could have strong impact on abundance estimations, particularly if only few observations are available within an area. Based on a scientific protocol, the CGFS sampling strategy is fixed and the timing of the survey almost does not vary from one year to the other. However, the EEC ecosystem constitutes for several species a migration path between the North Sea and the Atlantic Ocean, and this can lead to biased estimates of abundance based on survey conducted at a fixed period. For example, red mullet migrates during fall from the southern part of the North Sea to the Western English Channel (Mahé et al., 2005), but its migration timing appears variable across years (Carpentier et al., 2009), which could lead to high variance in some areas and thus causes difficulties to obtain a clear static mean distribution.

Pouting, poor cod, thornback ray and plaice have the lowest LIC in our results. Various species are known to change their behaviour between day and night (Pitcher, 1992), which may affect our results (Fréon et al., 1993). Indeed, pouting are known to have diel activity patterns, forming shoals near wrecks or rocks during the day and disperse during the night for feeding (Jensen et al., 2000). Thornback rays predate also at night and burry in the sand during the day (Wilding and Snowden, 2008). There is evidence that poor cod is mainly caught at night (Gibson et al., 1996). Concerning plaice, differences in catches between day and night are less clear and vary across studies (De Groot, 1971; Arnold and Metcalfe, 1995). Surveys like CGFS occur only during daylight, while about half of the fishing operations are 
conducted during the night. Including explicitly the time of the day in our model would be a way forward, which would require a larger set of data (Benoît and Swain, 2003). Finally, variability in species distribution can occur by environmentally-driven spatial and annual shifts (Verdoit et al., 2003). As previously evoked, with sufficient data, dealing with these shifts would require interaction parameters, introduced by fixed effects (with associated restrictions, e.g. Thorson and Ward, 2013) or random effects (with corresponding biascorrection, e.g. Thorson and Kristensen, 2016). The high number of presence/absence models that did not converge with an area-by-year interaction can be explained by the small number of observations for each occurrence (i.e. on average 2 per area-by-year), often 0 or 1 for a substantial part of the new parameters. Increasing the number of iteration failed to improve model convergence.

In the coming years, the growing collection of data may allow for accommodating such processes, but also fine-scale targeting (e.g. Thorson et al., in press), and hence lead to more reliable abundance estimates per area for a broader coverage of the EEC. A next step could then be to derive spatially-explicit estimations of fish lengths, building on innovative approaches (e.g. Petitgas et al., 2011; Nielsen et al., 2014). These could help to distinguish between mature and non-mature individuals, which are driving fish movement (Pittman and McAlpine, 2001).

\section{Uses of data collected on-board commercial vessels}

Another objective of this study was to provide annual series of abundance indices. The comparison between fisheries-dependent and -independent time series suggested contrasted results across species.

For species like cod (Figure 5a) and lemon sole, both the spatial and annual abundance distributions derived from fisheries and survey data were reasonably consistent. However, consistent annual trends across the two data sources were not necessarily linked with spatially 
overlapping distributions, e.g. cuttlefish or red mullet. Potential reasons for the lack of spatial overlap for such species were discussed above.

For other species, a good spatial overlap between fisheries-dependent and -independent abundance distributions was not necessarily associated with synchronous time series (e.g. black seabream, Figure $5 b$ ). This could be owing to data limitations, but also to some hyperstable relationship between abundance and CPUE (Hilborn and Walters, 1992), that could not be completely filtered out by our standardization approach. In addition, the species which present a good spatial overlap can be subject to intra-annual fluctuations of abundance owing to high exploitation, migrations and recruitment (Gillis and Peterman, 1998), that could strongly impact the mean annual abundance value.

Finally, abundance indices derived from fisheries data could be an appropriate source of information to provide seasonal and spatial distributions, particularly during periods where surveys do not operate. A better overview of species migrations is first a progress in current knowledge on species ecology, which could further be linked with seasonally-explicit abiotic and biotic environmental conditions. Secondly such information could be linked with fishers' movement throughout year, which could enhance our knowledge on fishers-resource interactions. Thirdly, seasonally- and spatially-resolved information such as that output from this study could also serve to calibrate complex end-to-end models such as Atlantis (Fulton et al., 2007), OSMOSE (Shin and Cury, 2001), ISIS-Fish (Pelletier et al., 2009) or Ecospace (Walters et al., 1999), and enhance their capacity to evaluate ecosystem-based management strategies (e.g. closed areas and seasons). Finally, further studies could validate the assumptions that on-board commercial data give a better overview of spatial distributions than survey for a small portion of species (e.g. pouting). However, the distributions derived for species presenting strong variability in selectivity or behavioural pattern (e.g. diel variations or migrations) should be interpreted with caution. 
In addition to spatial distributions, annual abundance indices derived from fisheries data could potentially complement the survey-based series used in stock assessments. This would require, as a follow-up to this study, to structure those fisheries-based annual indices by length and/or age, and perhaps to try to obtain such indices on a shorter duration than year. Previously, fisheries-based abundance indices should be closely examined, on a case-by-case basis, cognisant of the life cycle and exploitation features of the species under investigation.

\section{Conclusion}

This study shows the potential of combining fisheries-dependent and -independent data to increase our knowledge on the seasonal and spatial distribution of several marine species. Even if the comparisons realized during this study showed that fisheries-dependent data did not always mirror the time and spatial survey-based distribution of some species, they still remain a valid source of information. Fisheries-dependent data are relatively abundant, opportunistic and cheaper than survey data, and their use should be encouraged, especially to reflect abundance distributions in areas and seasons that are not covered by surveys.

Moreover, some species are poorly sampled by surveys owing to their diel behaviour, and the use of at-night observations on-board commercial vessels could help better inferring their spatial distributions. The method we used here is relatively simple compared with, e.g. logGaussian Cox model method developed by Kristensen et al. (2014). Still, the quality of the resulting outputs we presented was assessed, and these provide valuable information on spatial and temporal species distributions, which concur with existing ecological knowledge. This approach would benefit from a better spatial representation along the English coastline, and further cooperation, data sharing and on-board observation program strengthening could substantially enhance our understanding of the spatio-temporal distribution of marine species in the Eastern English Channel. 


\section{Supplementary material}

502 The following supplementary material is available at ICESJMS online: one table for

503 parameters of survey data models incorporating spatio-temporal interactions, one table for

504 comparison between models with and without spatio-temporal interactions and two tables of

505 parameters chosen for each species in the commercial data and survey data Delta-GLM. It

506 also contains additional abundance index from the two sources of data. Finally it contains

507 additional maps of the 18 species not presented in the study. 
509 This study was partly funded by the European Union's Horizon 2020 research and innovation 510 programme under Grant Agreement No 633680 (project DiscardLess). We are grateful to the

511 "Système d'Information Halieutique" (SIH), the "Marine Fisheries and Aquaculture

512 Administration"(DPMA) and all the persons involved in collecting and compiling survey

513 (CGFS) and on-board data (OBSMER program). The authors would also like to acknowledge

514 the Pôle Métropolitain de la Côte d'Opale for their financial supports. We also thank Antoine

515 Balazuc (Comité Régional de Pêches Maritimes du Nord Pas de Calais-Picardie) for his

516 valuable inputs. Finally we wish to thank James Thorson, the anonymous referees and editor

517 for helping us the improve manuscript. 


\section{References}

520

521

522

523

524

525

526

527

528

529

530

531

532

533

534

535

536

537

538

539

540

541

542

543

Arnold, G.P. and Metcalfe, J.D. 1995. Seasonal migrations of plaice (Pleuronectes platessa) through the Dover Strait. Marine Biology, 127: 151-160.

Auber, A., Travers-Trolet, M., Villanueva, M.C., and Ernande, B. 2015. Regime Shift in an

Exploited Fish Community Related to Natural Climate Oscillations. PLoS ONE 10(7):

e0129883. doi:10.1371/journal. pone.0129883

Benoît, H.P., \& Swain, D.P. 2003. Accounting for length- and depth-dependent diel variation in catchability of fish and invertebrates in an annual bottom-trawl survey. ICES Journal of

Marine Science, 60: 1298-1317.

Bertignac, M., Fernández, C., and Methot, R. 2012. Preliminary Spatially Disaggregated

Stock Assessment of Northern Hake, A Widely Distributed Stock of the Northeast Atlantic.

\section{ICES CM.}

Bivand, R., Altman, M., Anselin, L., Assuncaõ, R., Berke, O., Bernat, A., Blanchet, G., et al. 2013. spdep: Spatial Dependence: Weighting Schemes, Statistics and Models. CRAN—R package version $0.5-68$.

Booth, A. 2000. Incorporating the spatial component of fisheries data into stock assessment models. ICES Journal of Marine Science, 57: 858-865.

Carpentier A., Martin, C.S., and Vaz, S. (Eds.). 2009. Channel Habitat Atlas for marine Resource Management, final report / Atlas des habitats des ressources marines de la Manche orientale, rapport final (CHARMphase II). INTERREG 3a Programme, IFREMER,

Boulogne-sur-Mer, France. 626 pp. \& CD-rom.

Coppin, F., Travers-Trolet, M. 1989. CGFS : Channel Ground Fish Survey, http://dx.doi.org/10.18142//11

Cormon, X., Loots, C., Vaz, S., Vermard, Y., and Marchal, P. 2014. Spatial interactions between saithe (Pollachius virens) and hake (Merluccius merluccius) in the North Sea. ICES 
Journal of Marine Science, 71: 1342-1355.

Cornou A.-S., Quinio-Scavinner M., Delaunay D., Dimeet J., Goascoz N., Dube B., Fauconnet L., and Rochet M.-J. 2015. Observations à bord des navires de pêche professionnelle. Bilan de l'échantillonnage 2014. http://dx.doi.org/10.13155/39722 Dauvin, J.-C. 2012. Are the eastern and western basins of the English Channel two separate ecosystems? Marine Pollution Bulletin, 64: 463-471.

Dickson, W., Smith, A., and Walsh, S., 1995. Methodology manual: measurement of fishing gear selectivity. The Department of Fisheries and Oceans, Canada.

Dormann, C.F., McPherson, J.M., Araújo, M.B., Bivand, R., Bolliger, J., Carl, G., Davies, R.G., et al. (2007). Methods to account for spatial autocorrelation in the analysis of species distributional data: a review. Ecography, 30: 609-628.

Dray, S. 2013. spacemakeR: Spatial Modelling. R-Forge—R package version 0.0-5. Dray, S., Legendre, L., and Blanchet, F. 2013. packfor: Forward Selection with permutation (Canoco p.46). R-Forge-R package version 0.0-8.

Eigaard, O., Marchal, P., Gislason, H., and Rijnsdorp, A.D. 2014. Technological development and fisheries management. Reviews in Fisheries Science \& Aquaculture, 22: 156-174.

Eltink, A., Warmerdam, M., and Heinen, A. 1986. Origin, migration and spawning of southern North Sea mackerel with respect to the overspill of Western mackerel to the North Sea stock. ICES C.M. 1986/H:49, 15 pp.

Fauconnet, L., Trenkel, V.M., Morandeau, G., Caill-Milly, N., and Rochet, M.-J. 2015.

Characterizing catches taken by different gears as a step towards evaluating fishing pressure on fish communities. Fisheries Research, 164: 238-248.

Fréon, P., Gerlotto, F., and Misund, O.A. 1993. Consequences of fish behaviour for stock assessment. ICES Marine Science Symposia, 196 : 190-195. 
Fulton, E.A., Smith, A.D.M., and Smith, D.C. 2007. Alternative Management Strategies for Southeast Australian Commonwealth Fisheries: Stage 2: Quantitative Management Strategy Evaluation. Australian Fisheries Management Authority Report.

Gibson, R.N., Robb, L., Burrows, M.T., and Ansell, A.D. 1996. Tidal, diel and longer term changes in the distribution of fishes on a Scottish sandy beach. Marine Ecology Progress Series, 130: 1-17.

Gillis, D.M., and Peterman, R.M. 1998. Implications of interference among fishing vessels and the ideal free distribution to the interpretation of the CPUE. Canadian Journal of Fisheries and Aquatic Sciences, 55: 37-46.

Gillis, D.M. 2003. Ideal free distributions in fleet dynamics: a behavioral perspective on vessel movement in fisheries analysis. Canadian Journal of Zoology. 81: 177-187.

Groot, S.J. de. 1971. On the interrelationship between morphology of the alimentary tract, food and feeding behavior in flatfishes (Pisces: Pleuronectiformes). Netherlands Journal of Sea Research, 5: 121-196.

Hickford, M.J.H., and Schiel, D.R. 1996. Gillnetting in southern New Zealand: duration effects of sets and entanglement modes of fish. Fishery Bulletin, 94: 669-677.

Hilborn, R., and Walters, C.J. 1992. Quantitative fisheries stock assessment: Choice, dynamics and uncertainty. Chapman and Hall. 570 pp.

Horn, H.S. 1966. Measurement of "Overlap" in Comparative Ecological Studies. The American Naturalist, 100: 419-424.

Hunter, E., Berry, F., Buckley, A.A., Stewart, C., and Metcalfe, J.D. 2006. Seasonal migration of thornback rays and implications for closure management: Ray migration and closure management. Journal of Applied Ecology, 43: 710-720.

ICES. 2015. Report of the Herring Assessment Working Group for the Area South of $62^{\circ} \mathrm{N}$ (HAWG), 10-19 March 2015, ICES HQ, Copenhagen, Denmark. ICES CM 2015/ACOM:06. 
850 pp.

Jensen, A.C., Collins, K.J., and Lockwood, A.PM. (Eds.) 2000. Artificial reefs in European seas. Kluwer Academic, Netherlands, 508 pp.

Kristensen, K., Thygesen, U.H., Andersen, K.H., and Beyer, J.E.. 2014. Estimating spatiotemporal dynamics of size-structured populations. Canadian Journal of Fisheries and Aquatic Sciences, 71: 326-336.

Larsonneur, C., Bouysse, P., and Lauffret, J-P. 1982. The superficial sediments of the English Channel and its Western Approaches. Sedimentology, 29: 851-864.

Legendre, P. 1993. Spatial autocorrelation — trouble or new paradigm? Ecology, 74: 16591673.

Lo, N.C., Jacobson, L.D., and Squire, J.L. 1992. Indices of relative abundance from fish spotter data based on Delta-Lognormal Models. Canadian Journal of Fisheries and Aquatic Sciences, 49: 2515-2526.

Long, R.D., Charles, A., and Stephenson, R.L. 2015. Key principles of marine ecosystembased management, Marine Policy, 57: 53-60.

Mahé K., Destombes A., Coppin F., Koubbi P., Vaz S., Leroy D. and Carpentier A. 2005. Le rouget barbet de roche Mullus surmuletus (L. 1758) en Manche orientale et mer du Nord, 186 pp.

Marchal, P., Andersen, B., Bromley, D., Iriondo, A., Mahévas, S., Quirijns, F., Rackham, B., Santurtun, M., Tien, N., and Ulrich, C. 2006. Improving the definition of fishing effort for important European fleets by accounting for the skipper effect. Canadian Journal of Fisheries and Aquatic Sciences, 63: 510-533.

Maunder, M.N., and Punt, A.E. 2004. Standardizing catch and effort data: a review of recent approaches. Fisheries Research, 70: 141-159. 
Meissa, B., Rivot, E., and Gascuel, D. 2008. Analysis of CPUE data series through

Generalized Linear Models and Delta method to derive annual series of abundance indices Application to the Mauritanian demersal fishery. Scientific report European project ISTAM, Deliverable D.3.2, Agrocampus Ouest, Rennes. 13 pp.

Meyer, C.G., Holland, K.N., and Papastamatiou, Y.P. 2007. Seasonal and diel movements of giant trevally Caranx ignobilis at remote Hawaiian atolls: implications for the design of marine protected areas. Marine Ecology Progress Series, 333: 13-25.

Molfese, C., Beare, D., and Hall-Spencer, J. 2014. Overfishing and the Replacement of Demersal Finfish by Shellfish: An Example from the English Channel. PLoS ONE 9(7): e101506. doi: 10.1371/journal.pone.0101506.

Nielsen, J.R., Kristensen, K., Lewy, P., and Bastardie, F. 2014. A Statistical Model for Estimation of Fish Density Including Correlation in Size, Space, Time and between Species from Research Survey Data. PLOS ONE 9(6): e99151. doi:10.1371/journal.pone.0099151. Pawson, M.G. 1995. Biogeographical identification of English Channel fish and shellfish stocks. Technical report 99, MAFF, Directorate of Fisheries Research, Lowesoft, 72 pp. Pawson, M. G., Pickett, G. D., Leballeur, J. Brown, M., and Fritsch, M. 2007. Migrations, fishery interactions, and management units of sea bass (Dicentrarchus labrax) in Northwest Europe. ICES Journal of Marine Science, 64: 332-345.

Pelletier D., Mahevas S., Drouineau H., Vermard Y., Thebaud O., Guyader O., and Poussin B. 2009. Evaluation of the bioeconomic sustainability of multi-species multi-fleet fisheries under a wide range of policy options using ISIS-Fish. Ecological Modelling, 220(7): 10131033.

Petitgas, P., Doray, M., Masse, J., and Grellier, P. 2011. Spatially explicit estimation of fish length histograms, with application to anchovy habitats in the Bay of Biscay. ICES Journal of Marine Science, 68: 2086-2095. 
642 Pitcher, T.J. 1992. The Behaviour of Teleost Fishes (ed. T.J. Pitcher). London:Chapman and 643 Hall. $716 \mathrm{pp}$

644 Pittman, S.J., and McAlpine, C.A. 2001. Movements of marine fish and decapods 645 crustaceans: Process, theory and application. Advance in Marine Biology, An Annual 646 Review, 44: 206-295.

647 Ravard, D., Brind'Amour, A., and Trenkel, V.M. 2014. Evaluating the potential impact of 648 fishing on demersal species in the Bay of Biscay using simulations and survey data. Fisheries 649 Research, 157: 86-95.

650 Renard, D., Bez, N., Desassis, N., Beucher, H., and Ors, F. 2014. RGeostats: Geostatistical 651 Package. R Package version 10.0.8. MINES-ParisTech / ARMINES. Free download from: 652 http://cg.ensmp.fr/rgeostats

653 Rijnsdorp, A.D., Daan, N., Dekker, W., Poos, J.J., and Van Densen, W.L.T. 2007. Sustainable 654 use of flatfish resources: Addressing the credibility crisis in mixed fisheries management. 655 Journal of Sea Research, 57: 114-125.

656 Royer, J., Périès, P., and Robin, J.-P. 2002. Stock assessments of English Channel loliginid 657 squids: updated depletion methods and new analytical methods. ICES Journal of Marine 658 Science, 59: 445-457.

659 Royer, P., Pierce, G.J., Foucher, E., and Robin, J.-P. 2006. The English Channel stock of 660 Sepia officinalis: Modelling variability in abundance and impact of the fishery. Fisheries 661 Research, 78(1): 96-106.

662 Scrimgeour, G.J., and Winterbourn, M.J. 1987. Diet, food resource partitioning and feeding 663 periodicity of two riffle-dwelling fish species in a New Zealand river. Journal of Fish 664 Biology, 31: 309-324.

665 Shin, Y.-J., and Cury, P. 2001. Exploring fish community dynamics through size-dependent 666 trophic interactions using a spatialized individual-based model. Aquatic Living Resources, 14: 
65-80.

Skerritt, D.J. 2010. A review of the European flounder Platichthys flesus - biology, life history and trends in population. Eastern Sea Fisheries Joint Committee report. Newcastle University. $13 \mathrm{pp}$.

Thorson, J.T., and Ward, E. 2013. Accounting for space-time interactions in index standardization models. Fisheries Research, 147: 426-433. doi:10.1016/j.fishres.2013.03.012. Thorson, J.T., Fonner, R., Haltuch, M.A., Ono, K., and Winker, H. In press. Accounting for spatiotemporal variation and fisher targeting when estimating abundance from multispecies fishery data. Canadian Journal of Fisheries and Aquatic Sciences, 73: 1-14.

Thorson, J.T., and Kristensen, K. 2016. Implementing a generic method for bias correction in statistical models using random effects, with spatial and population dynamics examples. Fisheries Research, 175: 66-74. doi:10.1016/j.fishres.2015.11.016. Van Keeken, O.A., van Hoppe, M., Grift, R.E., and Rijnsdorp, A.D. 2007. Changes in the spatial distribution of North Sea plaice (Pleuronectes platessa) and implications for fisheries management. Journal of Sea Research, 57: 187-197.

Vaz, S., Carpentier, A., and Coppin, F., 2007. Eastern English Channel fish assemblages: measuring the structuring effects of habitats on distinct sub-communities. ICES Journal of Marine Science, 64: 271-287.

Verdoit, M., Pelletier, D., and Bellail, R. 2003. Are commercial logbook and scientific CPUE data useful for characterizing the spatial and seasonal distribution of exploited populations? The case of the Celtic Sea whiting. Aquatic Living Resources, 16: 467-485.

Walters, C., Pauly, D., and Christensen, V. 1999. Ecospace: prediction of mesoscale spatial patterns in trophic relationships of exploited ecosystems, with emphasis on the impacts of marine protected areas. Ecosystems, 2: 539-554.

Wilding., C., and Snowden., E. 2008. Raja clavata. Thornback ray. Marine Life Information 
692 Network: Biology and Sensitivity Key Information Sub-programme [on-line]. Plymouth:

693 Marine Biological Association of the United Kingdom. [cited 25/11/2011]. Available from:

694 http://www.marlin.ac.uk/speciesinformation.php?speciesID=4229

695 Woillez, M., Rivoirard, J., and Petitgas, P. 2009. Notes on survey-based spatial indicators for 696 monitoring fish populations. Aquatic Living Resources, 22: 155-164.

697 
Table 1. List of species considered in this study, with their minimum total length $L_{s}(\mathrm{~cm})$, above which individuals are considered to be equally selected by survey and commercial gears, and Minimum Landing Size (MLS) during the 2003-2014 period in Eastern English

701 Channel when relevant.

\begin{tabular}{lccc}
\hline \multicolumn{1}{c}{ species } & $\mathbf{L}_{\mathbf{s}}(\mathbf{c m})$ & MLS $(\mathbf{c m})$ & Common name \\
\hline Chelidonichthys cuculus & 22 & - & Red gurnard \\
\hline Chelidonichthys lucerna & 26 & - & Tub gurnard \\
\hline Dicentrarchus labrax & 36 & 36 & European seabass \\
\hline Gadus morhua & 35 & 35 & Atlantic cod \\
\hline Limanda limanda & 21 & - & Common dab \\
\hline Loligo spp. & $14^{\text {a }}$ & - & Squids \\
\hline Merlangius merlangus & 24 & 27 & Whiting \\
\hline Microstomus kitt & 25 & - & Red mullet \\
\hline Mullus surmuletus & 20 & - & Starry smooth-hound \\
\hline Mustelus asterias & 60 & - & European flounder \\
\hline Platichthys flesus & 29 & - & European plaice \\
\hline Pleuronectes platessa & 25 & 27 & Thornback ray \\
\hline Raja clavata & 49 & - & Lesser-spotted dogfish \\
\hline Scyliorhinus canicula & 54 & - & Common cuttlefish \\
\hline Sepia officinalis & $13^{\text {a }}$ & - & Black seabream \\
\hline Spondyliosoma cantharus & 17 & - & Pouting \\
\hline Trisopterus luscus & 25 & - & Poor cod \\
\hline Trisopterus minutus & 13 & - & John Dory \\
\hline Zeus faber & 21 & - & \\
\hline & & ${ }^{a}$ mantle length & \\
\hline
\end{tabular}


Table 2. Jackknife results and main data attributes for species that did not initially demonstrate significant overlap between OBSMER and Channel Ground Fish Survey (CGFS) distributions. LIC: original value of Local Index of Collocation. p-value: situation of the LIC value related to the distribution of permutation tests (values below 0.05 indicate significant overlap). JK: number of areas which prevented from having significant overlap (with total number of areas). \% abundance OBSMER \& CGFS: percentage of abundance represented by these sensitive areas among all OBSMER and CGFS areas respectively (with ranking among all areas).

\begin{tabular}{cccccc}
\hline LIC & p-value & JK & $\begin{array}{c}\% \\
\text { abundance } \\
\text { OBSM }\end{array}$ & $\begin{array}{c}\% \\
\text { abundance } \\
\text { CGFS }\end{array}$ \\
\hline Seabass & 0.49 & 0.156 & $0(24)$ & $/$ & $/$ \\
\hline Squids & 0.54 & 0.440 & $0(20)$ & $/$ & $/$ \\
\hline Red mullet & 0.58 & 0.063 & $2(23)$ & $5.8(4 / 23)$ & $12.4(2 / 23)$ \\
& & & & $3.7(8 / 23)$ & $19.2(1 / 23)$ \\
\hline Flounder & 0.47 & 0.118 & $0(21)$ & $/$ & $/$ \\
\hline Plaice & 0.32 & 0.194 & $0(24)$ & $/$ & $/$ \\
\hline Thornback ray & 0.22 & 0.703 & $0(22)$ & $/$ & $/$ \\
\hline Cuttlefish & 0.50 & 0.248 & $0(21)$ & $/$ & $/$ \\
\hline Pouting & 0.39 & 0.108 & $0(23)$ & $/$ & $/$ \\
\hline Poor cod & 0.10 & 0.768 & $0(21)$ & $/$ & $/$ \\
\hline John Dory & 0.67 & 0.259 & $0(24)$ & $/$ & $/$ \\
\hline
\end{tabular}


Table 3. Jackknife results and main data attributes for species that did initially demonstrate

716 significant overlap between OBSMER and Channel Ground Fish Survey (CGFS)

717 distributions. LIC: original value of Local Index of Collocation. p-value: situation of the LIC

718 value related to the distribution of permutation tests (values below 0.05 indicate significant

719 overlap). JK: number of areas which allowed having significant overlap (with total number of

720 areas). $\%$ abundance OBSMER \& CGFS: percentage of abundance represented by these

721 sensitive areas among all OBSMER and CGFS areas respectively (with rank among all areas).

\begin{tabular}{cccccc}
\hline & LIC & p-value & JK & $\begin{array}{c}\% \\
\text { abundance } \\
\text { OBSM }\end{array}$ & $\begin{array}{c}\% \\
\text { abundance } \\
\text { CGFS }\end{array}$ \\
\hline Red gurnard & 0.83 & $6 \mathrm{e}-04$ & $0(24)$ & $/$ & $/$ \\
\hline Tub gurnard & 0.79 & 0.016 & $1(24)$ & $11.1(2 / 24)$ & $11.3(1 / 24)$ \\
\hline Cod & & & & $1.9(2 / 24)$ & $0.7(19 / 24)$ \\
& & & & $0.0(23 / 24)$ & $1.2(14 / 24)$ \\
& 0.52 & 0.046 & $6(24)$ & $45.3(1 / 24)$ & $10.6(2 / 24)$ \\
& & & & $0.2(20 / 24)$ & $0.5(20 / 24)$ \\
& & & & $0.0(24 / 24)$ & $3.4(10 / 24)$ \\
\hline Common dab & 0.66 & 0.019 & $1(23)$ & $22.2(1 / 23)$ & $43.1(1 / 23)$ \\
\hline Whiting & 0.71 & 0.030 & $0(23)$ & $/$ & $/$ \\
\hline Lemon sole & 0.65 & 0.021 & $1(22)$ & $25.5(1 / 22)$ & $27.1(1 / 22)$ \\
\hline Lesser-spotted dogfish & 0.62 & 0.046 & $1(22)$ & $14.9(3 / 22)$ & $25.9(1 / 22)$ \\
\hline & 0.63 & 0.020 & $1(24)$ & $27.9(1 / 24)$ & $12.2(2 / 24)$ \\
\hline & & & & $0.2(18 / 23)$ & $1.0(17 / 23)$ \\
& & & & $0.0(20 / 23)$ & $0.1(22 / 23)$ \\
Black seabream & 0.67 & 0.043 & $8(23)$ & $0.2(17 / 23)$ & $0.3(20 / 23)$ \\
& & & & $7.8(5 / 23)$ & $12.6(3 / 23)$ \\
& & & & $0.0(23 / 23)$ & $1.6(13 / 23)$ \\
& & & & $14.8(2 / 23)$ & $12.7(2 / 23)$ \\
\hline
\end{tabular}


Table 4. Correlation between Channel Ground Fish Survey (CGFS) and OBSMER annual

725 abundance indices assessed by Pearson's correlation index (Pearson). LIC values are also 726 reported for 18 species Eastern English Channel species. Tub gurnard is not represented

727 because the year effect was not significant $(\mathrm{p}>0.05)$ in the survey model. * emphasizes

728 species for which spatial overlap was significant $(\mathrm{p}<0.05)$.

\begin{tabular}{ccc}
\hline Common name & Pearson & LIC \\
\hline Poor cod & 0.81 & 0.10 \\
\hline Cod & 0.72 & $0.52^{*}$ \\
\hline John Dory & 0.71 & 0.67 \\
\hline Red mullet & 0.66 & 0.58 \\
\hline Plaice & 0.65 & 0.32 \\
\hline Lemon sole & 0.63 & $0.65^{*}$ \\
\hline Cuttlefish & 0.51 & 0.50 \\
\hline Common dab & 0.24 & $0.66^{*}$ \\
\hline Red gurnard & 0.20 & $0.83^{*}$ \\
\hline Whiting & -0.01 & $0.71^{*}$ \\
\hline Starry smooth-hound & -0.05 & $0.62^{*}$ \\
\hline Thornback ray & -0.08 & 0.22 \\
\hline Squids & -0.12 & 0.54 \\
\hline Pouting & -0.13 & 0.39 \\
\hline Lesser-spotted dogfish & -0.22 & $0.63^{*}$ \\
\hline Black seabream & -0.23 & $0.67^{*}$ \\
\hline Flounder & -0.27 & 0.47 \\
\hline Seabass & -0.50 & 0.49 \\
\hline
\end{tabular}




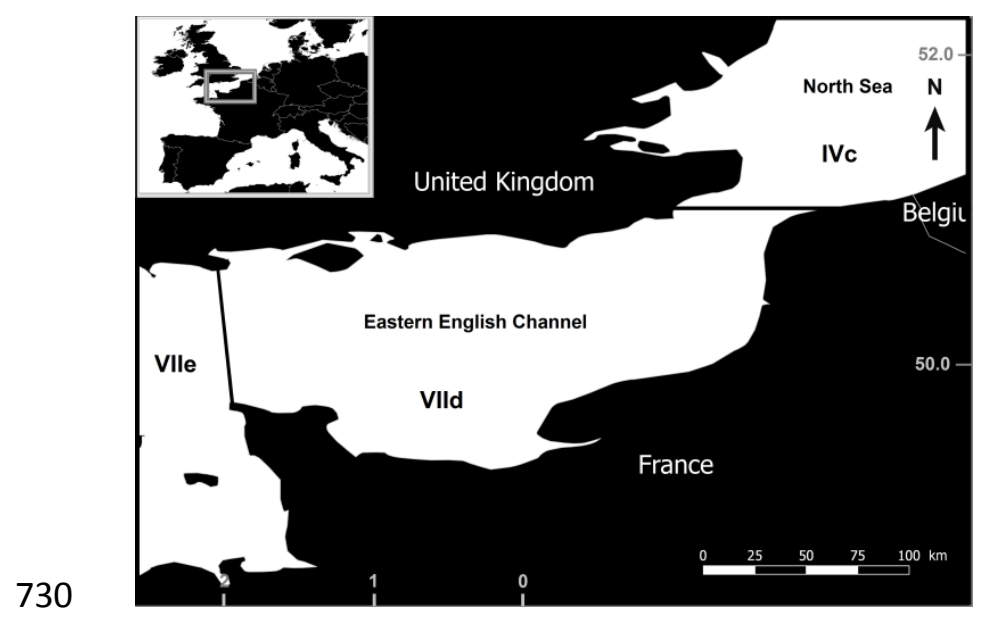

731 Figure 1. Study area of the Eastern English Channel, corresponding to the ICES division 732 VIId.

733

734

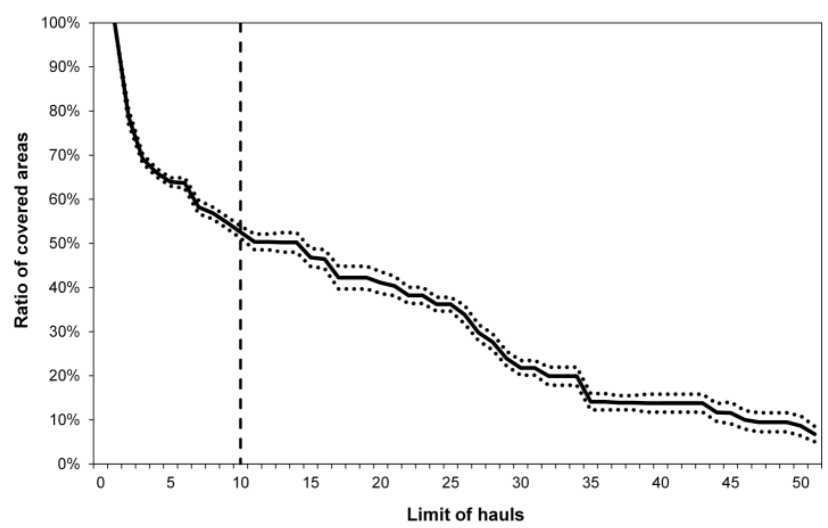

735 Figure 2. Mean percentage of cells kept in the analysis according to the minimal threshold of

736 hauls set per cell. Dotted lines represent the standard deviation along the 19 species. Dashed 737 vertical line represents the chosen limit of 10 observations. 

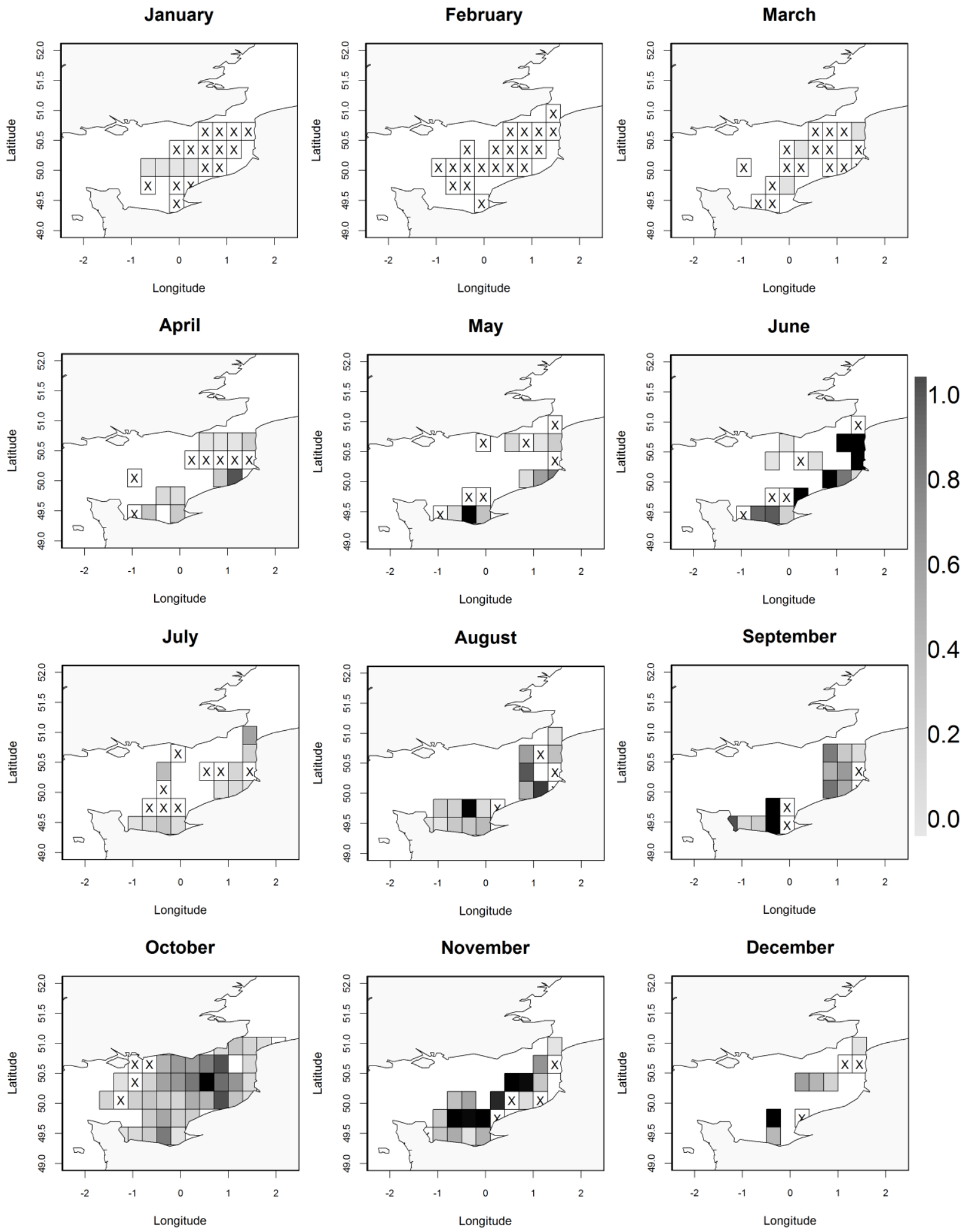

Figure 3. Monthly spatial abundance distribution estimated from OBSMER and CGFS for

741 cuttlefish. ' $\mathrm{X}$ ' represents areas where no cuttlefish was ever fished during a month in the 742 database. 


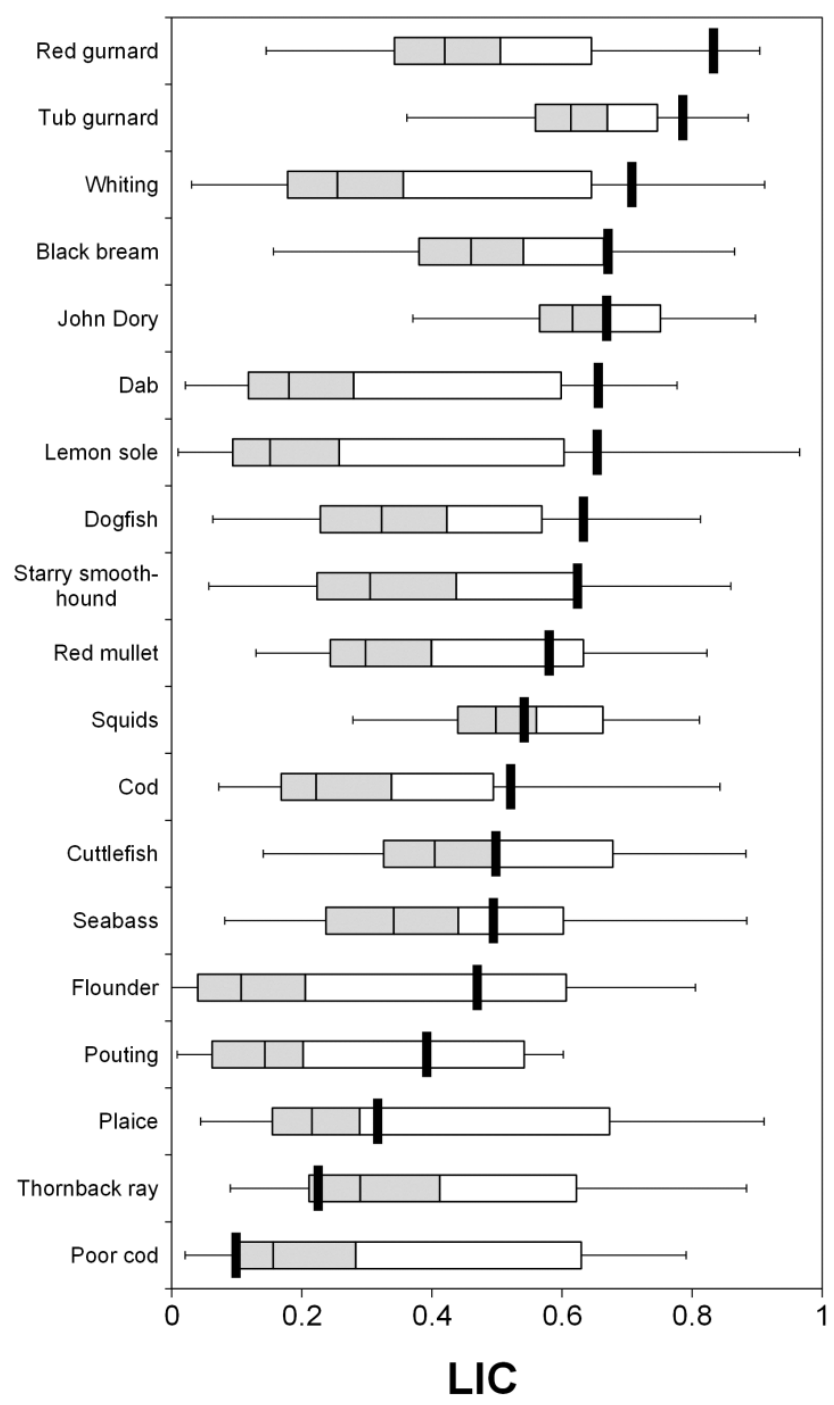

743

Figure 4. Actual Local Index of Collocation of the 19 species investigated in the Eastern

745 English Channel (bold black line), compared to the distribution of 5000 randomly simulated LICs (permutation test). Minimum and maximum simulated LIC are represented by the short

747 segments. Grey boxes represent Q1, median and Q3 ranges of simulated LICs. The white box represents the range of values between $\mathrm{Q} 3$ and the $95^{\text {th }}$ percentile of simulated LICs. 


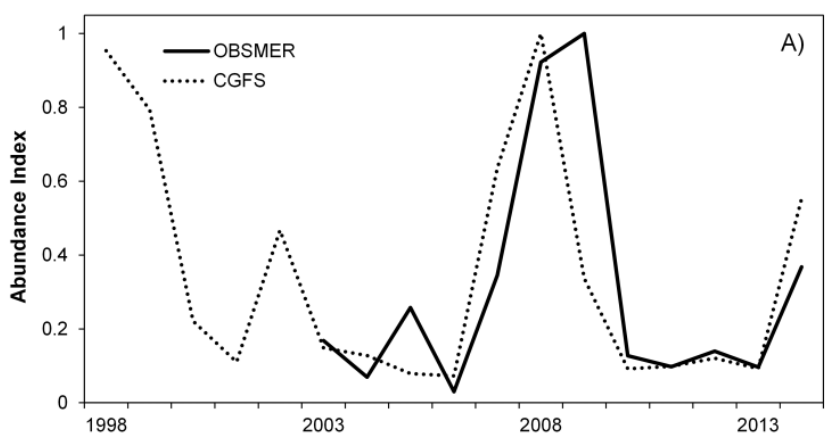

750

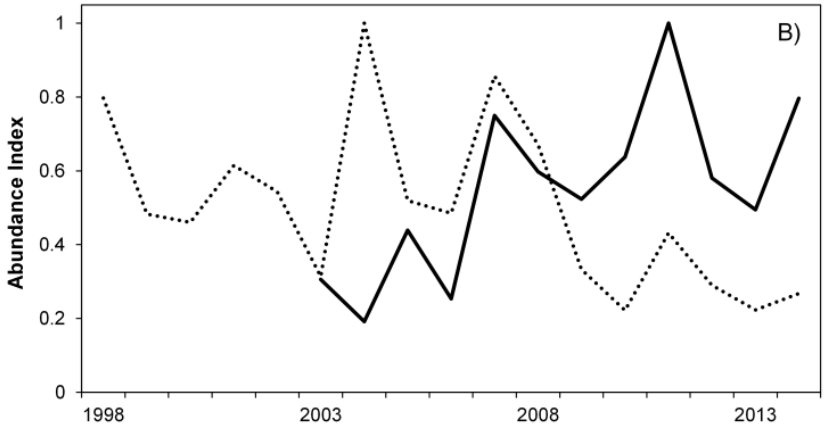

751 Figure 5. Annual abundance index estimated from Channel Ground Fish Survey (CGFS;

752 dotted line) and OBSMER (solid line) for A) cod and B) black seabream. 